\title{
A LEGITIMAÇÃO DO CONHECIMENTO ATRAVÉS DA NARRATIVA
}

\author{
LA LEGITIMACIÓN DEL CONOCIMIENTO A TRAVÉS DE LA NARRATIVA
}

Julya Célia Vieira Fiorese ${ }^{1}$

\begin{abstract}
Resumo: O presente relato de experiência parte de uma escrita-narrativa como alternativa ao modelo branco, academicista e cientificista de se pensar a produção de conhecimento. Processo esse que resultou de provocações do xamã yanomami Davi Kopenawa em seu livro, de produção conjunta com Bruce Albert, "A Queda do Céu: Palavras de um xamã Yanomami" (2015). Assim, relato minha experiência formativa acerca desse tema e trago o diálogo com outras formas de se pensar a narratividade, podendo ser através de uma escrita de Si (Foucault, 2006) ou pela produção de Arpillera (Lima, 2018), por exemplo. Essa proposta de escrita da oralidade só é possível a partir de um processo dialógico em que se prioriza a abertura à alteridade e que envolve o existir e conhecer numa mesma dimensão. Isso nos permite captar elementos que compõem a experiência yanomami e que escapam à simples transcrição de ideias para o papel por Albert.
\end{abstract}

Palavras-chave: Narrativa; Yanomami; Kopenawa; Arpillera; escrita.

Resumen: El presente informe de experiencia se basa en una escritura narrativa como alternativa al modelo blanco, académico y científico de pensar en la producción de conocimiento. Este proceso fue el resultado de las provocaciones del chamán yanomami Davi Kopenawa en su libro, producido conjuntamente con Bruce Albert, "La caída del cielo: palabras de un chamán yanomami" (2015). Así, doy cuenta de mi experiencia formativa sobre este tema y traigo el diálogo con otras formas de pensar la narratividad, que puede ser a través de una escritura de Si (Foucault, 2006) o la producción de Arpillera (Lima, 2018), por ejemplo. Esta propuesta de escritura de la oralidad sólo es posible desde un proceso dialógico en el que se prioriza la apertura a la alteridad y que implica existir y conocer en una misma dimensión. Esto permite captar elementos que conforman la experiencia yanomami y que escapan a la simple transcripción de ideas al papel por parte de Albert.

Palabras clave: Narrativa; Yanomami; Kopenawa; Arpillera; escrita.

Começar a escrever é sempre um desafio. Por isso, decido iniciar este relato de experiência falando sobre a escolha do tema desta escrita e da forma com que penso que ela irá se manifestar. Esta escrita é resultado de uma análise individual - no que tange a singularidade que atravessa meu corpo - do processo de aprendizado vivido ao longo de parte deste período pandêmico em que se foi exigida da comunidade universitária, escolar e (parte) trabalhadora a experiência de uma atividade remota. Por isso se torna impossível desconsiderar que tais elementos estão atravessados neste exercício de produção de sentido daquilo que foi estudado neste contexto.

O tema em questão se deve a um processo vivido ao longo destes meses de isolamento social, que me levou a uma aproximação a assuntos como produção de subjetividade, corpo, escrita e processos cognitivos. Em uma das disciplinas que optei realizar nesta etapa, a avaliação passava pela escolha de uma manifestação artística para se relacionar à produção de subjetividade e, atravessada pelas ideias de Kopenawa (2015) e Lima (2018) - esta última relacionada à produção de Arpilleras $^{2}$-, escolhi estudar a escrita como forma de narrativa de

\footnotetext{
${ }^{1}$ Universidade Federal do Espírito Santo, ES, Brasil.

${ }^{2}$ Entendendo Arpillera como um modo de resistência em forma de bordado que surgiu no Chile à época da Ditadura Militar chilena no exercício de Pinochet (Lima, 2018). O tema vem de uma das optativas realizadas neste semestre, em que estamos produzindo uma Arpillera.
} 
si. Este tipo de escrita me fez encontrar uma forma de incluir tudo o que é ignorado pela academia nas produções e que muito tem a ver com Davi Kopenawa (2015).

A narrativa permite este vivenciar e legitimar as experiências descritas, permite $o$ movimento de escrever a partir da oralidade. Por isso a minha recusa, antecipando às leitoras e leitores a minha proposta neste trabalho, em realizar uma escrita estritamente acadêmica, digo estritamente porque, por mais que haja a tentativa de se esquivar desse tipo de escrita, ela já foi incorporada em nós e recorremos a ela.

A escrita, para mim, vem de um lugar terapêutico, um exercício de constituição de si à medida em que se dá conta daquilo que se escreve e se legitima narrativas que não seriam consideradas ou até mesmo enxergadas. Principalmente as que falam do feminino. Acredito que o escrever exige que eu me debruce sobre minha história e, assim, assumo ela, legitimo ela, faço ela ser contada. É nesse sentido que, para mim, a escrita pode se relacionar tanto com a produção de Arpillera. A resistência em forma de narrativas contadas pelas agulhas e linhas se relaciona com minha forma de narrar a minha história e das mulheres de minha família através da escrita. Histórias estas que não estão presentes nas produções acadêmicas. Produções que ignoram o corpo, ignoram as relações, ignoram o processo inventivo. É a partir dessa escrita que tento incorporar, acoplar com o meio, um pouco da imensidão do compor-se Yanomami narrado por Kopenawa (2015), deixar que suas palavras me atravessem.

Aproveito, assim, para afirmar o aspecto ético-político-estético que se pretende manifestar esta escrita, entendidos como um meio de experimentação da diferença, afirmação da alteridade e acionamento de processos inventivos - que trazem a possibilidade de criação de si através da construção dessas ideias (Macedo e Dimenstein 2009). Para isso, pretendo realizar uma escrita inventiva que dê lugar ao corpo, voz àquilo que me constitui e abertura a essa experiência com objetivo de trazer uma forma outra de legitimação do conhecimento, que não seja a do academicismo e cientificismo. Talvez o trabalho seja justamente esse, de uma tentativa a não cair num paradoxo baseado em um esforço de desvincular a legitimidade de um conhecimento à prática escrita acadêmica a partir do próprio exercício de se escrever. Quero ressaltar que a legitimidade não é aqui dada por mim, mas já está dada em si mesma, através do processo em que se vive a construção desse conhecimento.

Narro, assim, por exemplo, a produção do meu diário de campo ao longo da construção da Arpillera. Ele teve muita influência de uma escrita que passa pela oralidade, inspirada nas narrativas de Kopenawa, que legitimam os aspectos constituintes da experiência. Foi um processo de resgate da memória, de autoconhecimento e de se localizar no mundo. Trago um fragmento do meu diário de produção para explicitar como a narratividade acompanhou toda a construção da minha escrita-bordada:

\begin{abstract}
"Concluo afirmando a potência que senti ao longo desse processo de resgate da memória, de rememorar e produzir sentido sobre esses pontos que me constituem, bem como minhas relações com meus familiares. Apesar de não ter falado sobre o processo estético da Arpillera neste documento, sinto que falei mais sobre ela do que qualquer outra coisa. Pensar em constituir uma Arpillera me fez sentar e organizar muitas questões. Agora pareço compreender mais. Agora me sinto mais próxima das disciplinas. Estou feliz!".
\end{abstract}

Também teve influência de Foucault (2006) quando traz a proposta de uma escrita como uma prática de Cuidado de Si e que abre espaço para uma produção estética e de aumento da potência. Essa prática diz sobre um certo jogo de conhecer e cuidar (de Lemos, 2017) e, pela via ética, escutar e experimentar a diferença (Macedo e Dimenstein, 2009). É isto que tento constituir aqui. Uma escrita que forma um corpo, considerando os aspectos que são anteriores a qualquer coisa dada 
sobre si. É reconhecer aquilo que subjetivou este corpo. É reconhecer as leituras e influências que antecederam. Desenhar nas "peles de papel" elementos que escapam à ordem da academia e que compõem a obra inteira de "A Queda do Céu: palavras de um xamã yanomami” (2015).

A preciosidade deste livro se dá pela potência que ele tem e que transmite. Em primeiro lugar porque a escrita tem uma estética que respeita e representa o processo da oralidade em que o texto foi produzido. Tal construção só foi possível a partir da oralidade. A riqueza dos relatos de Davi Kopenawa (2015) nos permite experienciar, quase que de forma presencial, suas falas. Mas não só isso. Os sentidos, a imaginação, o corpo, tudo é atravessado por essa outra experiência. Até mesmo a estrutura e organização do livro transmitem essa potência. É desta forma que o xamã se apropria da escrita dos brancos para justamente dar essa abertura à outra lógica de produção e legitimação de um conhecimento. Ele usa a escrita a seu favor. Ele não nos fala simplesmente através da nossa linguagem acadêmica e científica, mas subverte todos esses sentidos quando traz uma narrativa que permite a experienciação $o^{3}$ de uma outra epistemologia, de uma outra cosmovisão.

Bruce Albert (2015) não só transcreve as palavras de Davi de anos de conversas e vivências juntos, mas também localiza essas palavras, dá um chão e contexto para todos aqueles significados. Já no prólogo, Albert traz toda essa contextualização, fala sobre a vida de Kopenawa, sobre a história dos Yanomami no Brasil, sobre sua trajetória até seu encontro com Davi e o início de uma parceria e amizade. Ele fala sobre a produção do livro e também situa a grafia, pronúncia e glossário da escrita. Isso tudo evidencia uma tentativa de possibilitar a experiência através da leitura, não uma simples tradução e transcrição daquilo que foi dito pelo xamã. Esses elementos me permitiram mergulhar no universo Yanomami, como por exemplo, quando Albert (2015) traz a pronúncia da palavra “asi!", que indica raiva, ou a descrição física de como se pronuncia alguma palavra na tradução para o francês, mostrando o movimento que os lábios fazem na pronúncia, por exemplo.

Logo depois, há uma série de mapas que servem, literalmente, para localizar, dar nome, dar lugar a esse grupo que tem sido alvo de genocídio há tantos anos. Essas imagens dão mais força aos escritos anteriores sobre a história dos Yanomami no Brasil. Outro elemento importante, além da preservação do modo de descrição das experiências de Davi Kopenawa por Bruce Albert, este preserva também os desenhos realizados pelo líder yanomami.

Essa responsabilidade de Albert (2015) com a legitimidade de um certo exercício da oralidade pode ser percebida, também, neste trecho a seguir:

É oferecendo-as ao leitor assim, antes de qualquer comentário, em toda a potência de sua alteridade singular, que espero ter honrado o melhor que pude a tarefa de que ele me incumbiu, de fazer com que suas palavras fossem ouvidas e tivessem efeito em nosso mundo.(Albert; Kopenawa, 2015, p. 51).

Mas essa postura também foi fruto de um processo. Assim como todo o trabalho de escrita, que foi através de um exercício de Albert se debruçar sobre as gravações e anotações de anos de vivência com Davi, esse posicionamento de uma escrita responsável e que levasse todos os detalhes da narrativa de Kopenawa aos brancos também veio de uma iniciativa do mesmo. Como afirmado numa entrevista realizada em 17/10/18 para Souza e Nazareno (2020), o xamã diz que:

\footnotetext{
${ }^{3}$ Larrosa (2002) traz a experiência como aprendizado, em contraponto com a simples informação, como aquilo que nos passa, nos atravessa, sem a finalidade do "o que" se passa. É a partir desse sentido que trago experienciação, um processo que envolve intrínseca e integralmente o existir e conhecer.
} 
"O Bruce fez o documento dele, escreveu, peguei, abri, aí eu vi o nome do Yanomami falando ele contando pra nós, pro branco, sobre nós... Yanomami vive assim, Yanomami come macaco, Yanomami é povo nômade e só caça pesca e trabalha só isso. Então eu não gostei. Aí eu reclamei: "Olha, Bruce, você não consultou, você nem consultou de mim... aí ele: "Por quê?". Porque você entrou assim, é, sem permissão da comunidade, eu tava na outra aldeia, ele entrou na outra comunidade [...] então eu comecei a conversar com ele: "Agora tu vai, então eu vou deixar como você escreveu... fazer assim você vai me ajudar... quem vai contar sou eu não é tu... tu não é Yanomami, tu não nasceu na terra Yanomami, não. Você nasceu na França, então você aprendeu a nossa língua, você conheceu a nossa língua yanomami... você vai me ajudar aí"... demorou pouco, ele ficou triste ((Kopenawa sorri)), ficou triste e depois resolveu pensar, resolveu pensar e pra é... ele falou: "Toma... como você vai escrever?". "Eu vou gravar com o gravador, compra gravador, aí traz aqui na comunidade, nós vamo senta só nós dois"... Aí nós fizemo assim, aí eu fiquei preocupado: "Então quem vai contar histórico conhecimento do povo Yanomami sou eu, não é tu, você já fez, você conta a conhecimento da cidade capital... do que você conhece. Quem conhece essa floresta, o conhecimento do povo Yanomami, sou eu."' (SOUZA, 2020, p. 12).

Tendo esses elementos como fundamentais de uma perpetuação de costumes e tradições, somados à oralidade, Kopenawa (2015) faz uma crítica ao modo como os brancos precisam da escrita como uma forma de legitimar um certo conhecimento. E este é um ponto importante para aquilo que tenho tentado construir. Kopenawa (2015) ressalta o papel desta produção numa lógica macropolítica, que não se separa da micropolítica. O objetivo da escrita do livro partiu de uma necessidade de se narrar a nós, brancos, através da nossa linguagem - a escrita -, a história dos Yanomami, que pode ser semelhante à de outros povos da terra. De forma autônoma e desapegada, o xamã diz a Albert: "Você desenhou e fixou essas palavras em peles de papel, como pedi. Elas partiram, afastaram-se de mim. Agora desejo que elas se dividam e se espalhem bem longe, para serem realmente ouvidas." (Albert; Kopenawa, 2015, p. 64)

O modelo da escrita em relatos traz esse tom de narrativa falado anteriormente. Porém, tal produção se deu ao longo de muitos anos e como resultado de um processo extremamente dialógico. Pode-se perceber frequentemente um exercício de uma oralidade e escrita que se dão de forma complementar e constantemente atravessados pelos discursos cruzados entre o xamã e o antropólogo, bem como os aspectos que os compõem. "Os relatos dos episódios cruciais de sua vida mesclam inextricavelmente história pessoal e destino coletivo.” (Albert; Kopenawa, 2015, p. 50)

Já caminhando para o final desta escrita, porém sem o sentimento de conclusão ou de esgotamento daquilo que foi produzido, gostaria de trazer alguns elementos marcantes nesse processo e que, com certeza, continuarão perpetuando de diversas formas de provocações em mim. Uma característica do xamã, dentre tantas, que me capturou foi sua postura ético-política, que dá lugar à alteridade, ao diferente. Penso no xamã como referência justamente neste sentido de abertura, não como uma tentativa de minha conversão ao xamanismo, pelo menos não como na lógica cristã de conversão. Mas aprendendo com ele e abrindo espaço para uma outra cosmovisão, que não é a da destruição, da colonização, da supremacia, do egocentrismo e da individualidade. A proposta macropolítica de que ele traz se manifesta justamente no coletivo, nas consequências que vem para os brancos, para os povos da terra e para todos, humanos e não-humanos.

Saio desta leitura e escrita outra. Me sinto afetada, tocada, atravessada. Acredito que era isso que o xamã tinha em mente quando doou sua narrativa a nós. Sinto que compreendi um pouco da magnitude de uma questão tão complexa. Já me sinto mudada. É encantador como ele tem esse dom e me sinto mais potente em me abrir para essa visão de mundo outra e compreender a expressão 
singular em nossas diferenças. Diferenças estas que não falam sobre ele ser Yanomami e eu ser branca somente e prioritariamente, mas fala sobre essa possibilidade de abertura e afirmação da vida.

É lindo quando Viveiros de Castro (2006) diz que Kopenawa é "uma forma xamânica em si mesma, um exemplo de xamanismo em ação, no qual um xamã tanto fala sobre os espíritos para os Brancos, como sobre os Brancos a partir dos espíritos" (Castro, 2006, p. 320). Longe de se romantizar este trecho, a beleza vem justamente de se evidenciar o lugar do qual o xamã parte, que é outro, e se afirmar nessa diferença.

A existência dessa experiência se dá justamente no fato de não ser interpretada para e pelos brancos. E um sentimento presente na escrita deste texto é o de tentar legitimar uma compreensão da experiência trazida pelo livro "A Queda do Céu" (2015) através da escrita, caindo naquilo que Kopenawa (2015) traz afirmando que nós brancos precisamos desenhar nossas palavras porque elas são cheias de esquecimento. Assim, meu esforço se inclina para uma legitimação da experiência Yanomami, e não de minha compreensão sobre ela.

No mais, foi uma escrita ao mesmo tempo suave e pesada. Por mais que o objetivo e a tentativa fossem de uma produção estética inventiva, como falado no começo do texto, ainda há certo estranhamento de uma produção assim na academia. Tudo isso somado a uma experiência nova de contato com leituras de Kopenawa e sobre os yanomami, assumo o peso que essa escrita teve em alguns momentos. Nessa tentativa de realizar uma escrita inventiva e aberta, às vezes senti que essa descrição do processo e do contexto de produção poderiam ser um tipo de desperdício de páginas que poderiam ter sido usadas para elementos mais acadêmicos e científicos, ou até mesmo dar o sentimento de uma certa saturação de informações. Mas mesmo com essa sensação de insegurança, de um texto talvez informal, com ideias jogadas e talvez não tão bem estruturadas pela falta de experiência em escrever narrativas, sinto que tudo isso contribuiu para um processo de aprendizagem ético e me sinto bem. Tentei aqui um exercício de, porque não dizer, bordar palavras como na Arpillera; de desenhar palavras em peles de papel, como os Yanomami; de narrar palavras, como Kopenawa, em uma investida de produzir algo coletivo que afirme a alteridade. Por isso finalizo não com as minhas palavras, mas perpetuando essa tarefa de fazer com que as palavras dos yanomami sejam ouvidas, com um trecho do início do livro, Kopenawa, que é a narrativa incorporada, diz que:

“A floresta está viva. Só vai morrer se os brancos insistirem em destruí-la. (...) A terra ressecada ficará vazia e silenciosa. Os espíritos xapiri, que descem das montanhas para brincar na floresta em seus espelhos, fugirão para muito longe. Seus pais, os xamãs, não poderão mais chamá-los e fazê-los dançar para nos proteger. Não serão capazes de espantar as fumaças de epidemia que nos devoram. (...) Então morreremos, um atrás do outro, tanto os brancos quanto nós. Todos os xamãs vão acabar morrendo. Quando não houver mais nenhum deles vivo para sustentar o céu, ele vai desabar." (Albert; Kopenawa, 2015, p. 6).

\section{Referências}

BASTOS, R. K. L. A escrita como cuidado de si na obra tardia de Michel Foucault. Sísifo, Feira de Santana, v. 1, n. 5, 2017.

BONDÍA, J. L. Notas sobre a experiência e o saber de experiência. Revista Brasileira de Educação [online], n. 19, p. 20-28, 2002.

DE CASTRO, E. V. A floresta de cristal: notas sobre a ontologia dos espíritos amazônicos. Cadernos de Campo, São Paulo, 1991, n. 15 (14-15), p. 319-338, 2006. 
FOUCAUlT, M. Ética, sexualidade, política. In: MOTTA, M. B. (Org.). Ditos e Escritos V Tradução de: Elisa Monteiro Inês Autran Dourado Barbosa. Rio de Janeiro: Forense Universitária, 2006.

KOPENAWA, D; ALBERT, B. Kopenawa, Davi, and Bruce Albert. A queda do céu: palavras de um xamã yanomami. São Paulo: Editora Companhia das Letras, 2015.

LIMA, M. D. S. P. Arpilleras: o bordado como performance cultural chilena, em favor do drama social. Dissertação (Mestrado) - Universidade Federal de Goiás, Programa Interdisciplinar em Performances Culturais, Goiânia, 2018.

MACEDO, J. P; DIMENSTEIN, M. (2009). Escrita acadêmica e escrita de si: experienciando desvios. Mental, n. 7 (12), 153-166.

SOUZA, K. A. A; NAZARENO, E. "Experiências indígenas Com a Escrita: apropriação, Impasses, Desafios E Possibilidades: Educação Intercultural E ‘A Queda Do Céu”. Articulando E Construindo Saberes, v. 5, 2020.

\section{Sobre a autora}

Julya Célia Vieira Fiorese. Graduanda de Psicologia pela UFES.

E-mail: julyafiorese@ hotmail.com. 